\title{
Coronary artery bypass grafting: Learning to do common things uncommonly well
}

\author{
Tom C. Nguyen, MD
}

\section{See related article on pages 2720-6.}

When you can do the common things of life in an uncommon way, you will command the attention of the world.

\section{George Washington Carver}

More than a century ago, the renowned British surgeon Stephen Paget stated, "No new method and no new discovery can overcome the natural difficulties that attend a wound of the heart." ${ }^{1}$ This statement, however, has since been refuted by the many advances in cardiac surgery. Today, coronary artery bypass grafting (CABG) remains one of the most common operations performed by cardiac surgeons, with more than 300,000 procedures in the United States annually. ${ }^{2}$ Since the procedure's introduction, advances in CABG technique have minimized complications and adverse events.

Even though the procedure is both common and relatively low risk, the need for updating our literature with novel insights is mandatory for maintaining the highest possible level of patient care. As one of the most studied procedures in modern scientific literature, CABG outcomes need to be well reviewed and continuously audited. The analysis performed by Weisel and colleagues ${ }^{3}$ is much needed and represents a new reading into the perioperative management of the $\mathrm{CABG}$ procedure.

The study of Weisel and colleagues ${ }^{3}$ uses data from the trial Reduction in Cardiovascular Events by AcaDesine in Subjects Undergoing CABG (RED-CABG), ${ }^{4}$ one of the largest multicenter, randomized, double-blinded, placebocontrolled studies to assess cardiac events after nonemergency CABG for moderate- to high-risk patients. The primary efficacy end point of the study was a composite of death from any cause, nonfatal stroke, and severe left ventricular dysfunction requiring mechanical support within 28 days. Through the use of logistic regression modeling, the researchers identified baseline and intraoperative variables

\footnotetext{
From the Department of Cardiothoracic Surgery, University of Texas HoustonMemorial Hermann, Houston, Tex.

Disclosures: Author has nothing to disclose with regard to commercial support.

Received for publication Sept 8, 2014; accepted for publication Sept 8, 2014; available ahead of print Oct 3, 2014.

Address for reprints: Tom C. Nguyen, MD, Department of Cardiothoracic Surgery, University of Texas Houston-Memorial Hermann, 6400 Fannin, Suite 2850,

Houston, TX 77030 (E-mail: tom.c.nguyen@gmail.com).

J Thorac Cardiovasc Surg 2014;148:2727-8

$0022-5223 / \$ 36.00$

Copyright (c) 2014 by The American Association for Thoracic Surgery

http://dx.doi.org/10.1016/j.jtcvs.2014.09.009
}

associated with the primary outcome, including 4 preoperative risk factors, a history of heart failure, increasing age, a history of peripheral vascular disease, and taking aspirin before $\mathrm{CABG}$ (which had a protective effect), and 1 intraoperative variable, the duration of cardiopulmonary bypass.

Weisel and colleagues ${ }^{3}$ are to be commended for their analysis. Perhaps the most notable finding was that a history of heart failure independently contributed more to adverse outcomes than did a low ejection fraction, suggesting that patients who have heart failure but preserved systolic function warrant increased attention when undergoing CABG. Although heart failure is recognized as an inherent risk factor, the relative contribution of heart failure versus ejection fraction to CABG outcomes has not been well studied. This finding thus could serve to create an important paradigm shift as we strive for better risk stratification of patients before CABG.

Although this effect has previously been reported, this study also emphasized the importance of preoperative aspirin. The composite outcome rate among patients taking preoperative aspirin was half that of those who were not $(4.58 \%$ vs $8.72 \%$ ). The benefits of preoperative and early postoperative administration of aspirin have been well documented, and this study further underscores aspirin's value. As it stands, preoperative aspirin is a class I indication according to the 2011 American College of Cardiology and American Heart Association' guideline for CABG. It is not, however, a Society of Thoracic Surgeons quality performance measure. ${ }^{5}$ The results from this study suggest that perhaps it should be.

One notable limitation of the analysis was the narrow primary efficacy end points for the trial. It is unclear why other highly prevalent morbidities also associated with postoperative outcomes in CABG, such as renal failure, were not considered. This seems especially relevant to the high-risk group of patients included in the RED-CABG trial. Weisel and colleagues ${ }^{3}$ state that patients with preoperative renal dysfunction were excluded to avoid complications associated with acadesine treatment; however, this limitation should be considered when extrapolating these findings to the high-risk CABG population, which has a high prevalence of renal dysfunction.

An additional limitation relates to study design. The original study was designed to test the impact of acadesine on outcomes after CABG, and the limitations in using such a study to identify general predictors of outcome after $\mathrm{CABG}$ are substantial. For example, the original trial sought to determine the effect of acadesine rather than to evaluate predictors of outcome. 
Despite these limitations, Weisel and colleagues ${ }^{3}$ are to be congratulated on their contribution. Although CABG is common, its widespread use necessitates the continuous evaluation of outcomes to maintain the highest level of patient care. As George Washington Carver notes, "When you can do the common things of life in an uncommon way, you will command the attention of the world."

\section{References}

1. Davies MK, Hollman A. History of cardiac surgery. Heart. 2002;87:509.

2. Go AS, Mozaffarian D, Roger VL, Benjamin EJ, Berry JD, Blaha MJ, et al; American Heart Association Statistics Committee and Stroke Statistics Subcommittee. Executive summary: heart disease and stroke statistics-2014 update: a report from the American Heart Association. Circulation. 2014;129:399-410.

3. Weisel RD, Nussmeier N, Newman MF, Pearl RG, Wechsler AS, Ambrosio G, et al; the RED-CABG Executive and Steering Committees. Predictors of contemporary coronary artery bypass grafting outcomes. J Thorac Cardiovasc Surg. 2014;148:2720-6.

4. Newman MF, Ferguson TB, White JA, Ambrosio G, Koglin J, Nussmeier NA, et al; RED-CABG Steering Committee and Investigators. Effect of adenosine-regulating agent acadesine on morbidity and mortality associated with coronary artery bypass grafting: The RED-CABG randomized controlled trial. JAMA. 2012;308:157-64.

5. Hillis LD, Smith PK, Anderson JL, Bittl JA, Bridges CR, Byrne JG, et al. 2011 ACCF/AHA guideline for coronary artery bypass graft surgery: a report of the American College of Cardiology Foundation/American Heart Association Task Force on Practice Guidelines. Circulation. 2011;124:e652-735. Erratum in: Circulation. 2011;124:e957. 